\title{
LEARNING STYLES OF POST-SECONDARY VOCATIONAL EDUCATION STUDENTS AND HOTEL MANAGERS IN THE BAHAMAS
}

\section{Sophia Rolle}

Division of Social Sciences

The College of The Bahamas

\section{ABSTRACT}

This study sought to determine the learning styles of full-time post-secondary vocational educational students and general managers in The Bahamas. Data were as drawn from two groups, 94 full-time students at The Bahamas Hotel Training College (BHTC), and 24 hotel general managers using the Marshall and Merritt (1984) Learning Style Instrument with a Semantic Differential (LSI-SD), which is based on Kolb's Learning Style Model. Results of the study indicated that the majority of the students $(\mathrm{n}=44,50.7 \%)$ and managers $(\mathrm{n}=21,87.5 \%)$ had a diverger learning style. In other words, there is evidence that all full-time post-secondary students and hotel managers in this study had a predominant learning style that was measurable.

\section{INTRODUCTION}

It is important that people of all levels in the Caribbean grow to appreciate the importance of vocational and technological contributions to a society. The prerequisite to this understanding is providing knowledge and skills to people, and enabling them to understand and appreciate the vocational and technological environment. To this end, the Bahamian government saw fit to encourage unemployed persons with little or no technical or vocational skills to become trained. The Bahamas Hotel Training College (BHTC) was one of the institutions providing such training.

Vocational and technological education has been critiqued time and again by researchers who have determined that many vocational education institutions fail in their attempt to provide today's students with the skills needed for jobs within the industrial, vocational and manufacturing sectors. One of the objectives of this study then was to assess the learning styles of full-time post secondary vocational education students at BHTC and hotel general managers currently working in The Bahamas. Another objective was to compare predominant learning styles of these students to those of hotel general managers, and finally investigate the effects of such common demographic variables as nationality, age and gender and learning styles.

Several learning style models were reviewed to determine which one was most appropriate for achieving the objectives of this study. These included the Field Independence and Field Dependence model developed by Witkin, Goodenough, and Moore (1975), the Cognitive Style Mapping model developed by Hill and Nunney (1972), the Fuhrmann and Jacobs Model (1980), and the Kolb Learning Style Inventory (1984). Kolb's model was ultimately selected for use in this study because of its use with adult audiences. The alternate format with higher construct validity than Kolb's model, developed by Marshall and Meritt (1984), was selected for data collection.

During the late sixties and early seventies The Bahamas experienced an upsurge in the tourism and banking sectors of the economy. This was paralleled by a significant drop in activity in the related services industry such as the hospitality industry. Because of a failure to anticipate the need for suitable training programmes, the skills of the Bahamians did not match the needs in these emerging opportunities. In fact, it was estimated that well over one-third of the individuals who sought employment had no skills or 
work experience (Handbook of the Industrial Training College, 1991).

With this major growth in the tourism industry levelling the Bahamian government soon focused on other areas such as the technical and vocational fields, as potentially viable key elements in solving the demand for skilled labor in the dominant sectors of the economy. In the early 1980s, the Bahamian government identified four major socio-economic conditions which influenced its decision to make technical and vocational education a priority. These included: projections of continued youth unemployment and the social problems associated with it; the stablizing off of tourism-related jobs and the need to diversify; high migration from the Family Islands to the urban centers of Nassau and, Freeport, Grand Bahama due to lack of economic activities on the outer islands; and finally, the severe shortage of well-trained Bahamians in those technical areas in high demand. Adequate training was needed to accommodate this demand. Thus, the Bahamian government sought out technical and vocational schools already in existence, or sought to establish training centers to serve the identified needs. The Bahamas Hotel Training College one of the institutions established in 1973 was targeted as a hospitality training facility, its expressed mandate being to train present and future employees of hotel, tourism organizations, and allied industries. The philosophy rationalizing its remit extended to facilitating a total training and vocational center for the development of the tourist industry (Handbook of the Industrial Training Center, 1991).

\section{LEARNING STYLE MODELS}

The preceding discussion highlights some of the cognitive, social interaction and instructional preference learning style models that were both experientially based and met the objectives of this study.

\section{Cognitive Models}

These included Field Independence and Field Dependence developed by Witkin, Goodenough, and Moore (1975). The bases of this model is an individual's ability or inability to identify targeted stimuli from various backgrounds. Individuals who could not easily identify target stimuli from various backgrounds were thought to be field dependent learners. Those individuals who were not easily confused by background stimulation, were thought to be field independent learners.

Cognitive Style Mapping, another cognitive style learning model was developed by Hill and Nunney (1972). This model was developed to assess a person's preference for gathering information, thinking and making inferences, and making decisions that determine interest in self, other people, and surrounding objects. The senses, such as auditory and visual are thought to be primary in this gathering of information process. Hill's Cognitive Style Mapping Inventory utilized four broad categories in which a person's cognitive map is measured. These categories reflect the following ideas:

1. Education is the process of searching for meaning;

2. Thought is different from language;

3. Man is a social creature with a unique capacity for deriving meaning from his environment and personal experiences through the creation and use of symbols.

4. Not content with biological satisfaction alone, man continually seeks meaning (Hill \& Nunney, 1972).

These four categories are expanded into 27 specific cognitive characteristics. The Cognitive Style Mapping Inventory asks learners to rate themselves on 224 descriptive statements such as, "If I hear the daily news on the radio, I understand it better than if $I$ read it in the newspaper." Then each of the 27 learner characteristics is compiled and rated as major (true more than half of the time), minor (true less than half of the time), or negative (rarely true).

\section{Kolb's Learning Style Model}

Kolb's $(1976,1984)$ model of experiential learning provides the basis for this study because of its adult learner orientation and context. Kolb's (1984) model extends over four traits in acquiring informa- 
tion and leaming skills. These traits are Concrete experience (CE), Reflective Observation (RO), Abstract Conceptualization (AC), and Active Experimentation (AE). Concrete experience involves oneself fully in a new experience and seeks out additional experiences so that all the senses can be utilized firsthand. Reflective observation involves observing other people doing things and trying to emulate those experiences or developing observations about personal experiences in a learning environment. Abstract conceptualization is the creating of concepts and theories to explain the world. Active experimentation is using the theories and concepts a learner has acquired to solve problems and make decisions.

According to Kolb (1984), these traits comprise four models of human learning for which an individual can move from a very concrete experience to one that is highly abstract in nature. Although this flow seems typical, Kolb notes that individuals vary in their relative emphasis on, or preference for, each mode. Figure 1 depicts the dimensions or continua for which Kolb found the traits to be grouped. According to Kolb, abstract conceptualization-concrete experience (AC-CE) comprised one continua, while active experimentation-reflective observation (AE-RO) comprised the other continua. The transaction among the four learning traits and the resolution of transformation of the adaptive dialectics provide the structural basis of the learning process for Kolb's learning style types (converger, assimilator, diverger and accommodator).

Figure 1

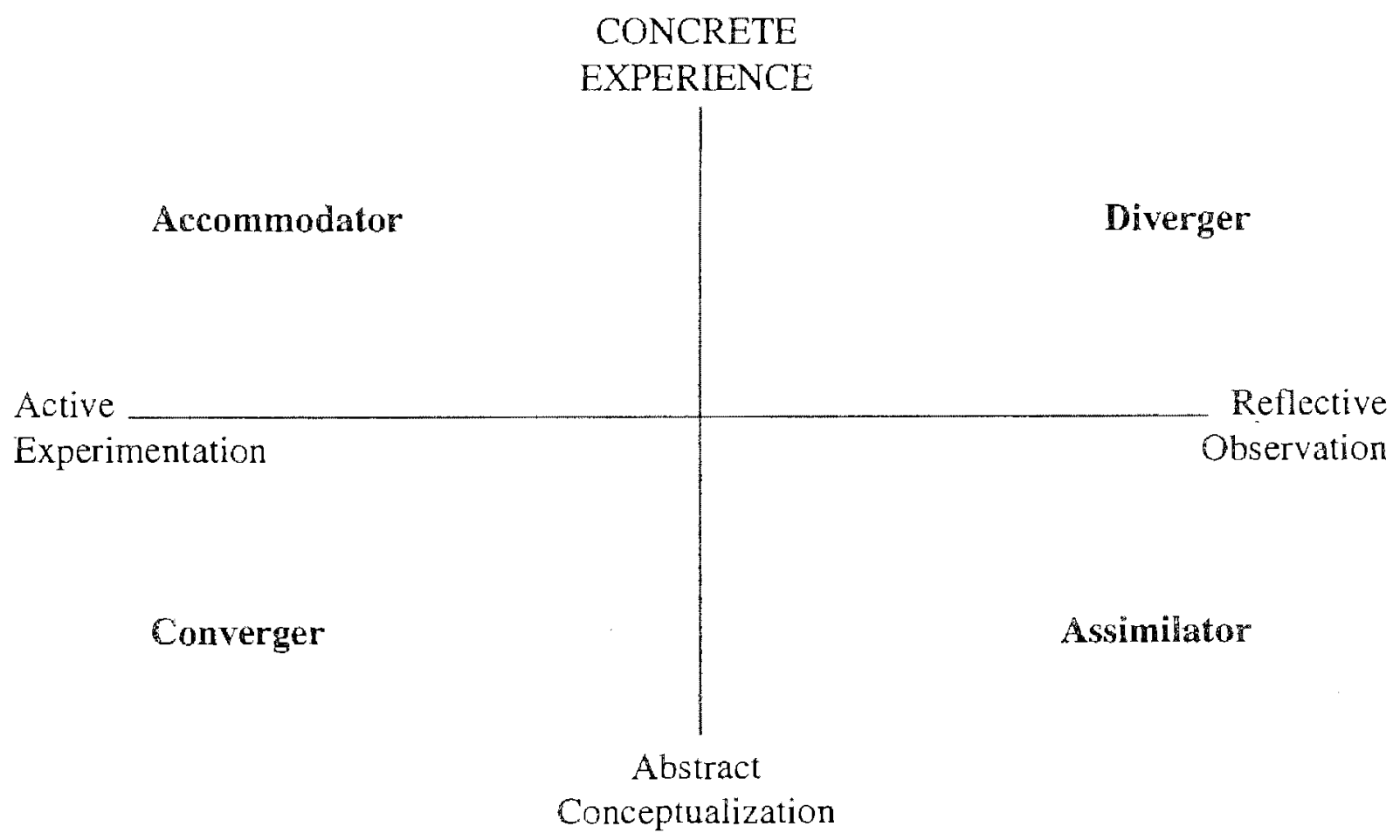




\section{Social Interaction Models}

This group of models are typically used to identify cognate or like features of interactions that learners have and the role these features play in the learning process (Fuhrmann \& Jacobs, 1980). Both the Fuhrmann and Jacobs model and the Grasha-Riechmann model share a similar trait. Both models require an individual to be in structured settings in order that learning styles might be noted. In the Fuhrmann and Jacobs model, an individual's learning style is determined while they are in one of these three modes: "dependent prone" where individuals need highly structured settings in which to function; "independent prone" where more flexibility is required to function, or the "collaborative prone" which is a combination of the two prones.

The Grasha-Riechmann model identifies a person's learning style through a series of role playing exercises. These roles include: competitive, collaborative, dependent, independent, participant, and avoidant.

\section{Instructional Preference Models}

Although these models are relatively new in the area of determining student learning styles, their relevance for discovering the preferences that students have for study methods, instructional media, course format, and other dimensions of classroom-related learning were important to this research. Both models reviewed for this study, the Learning Preference Inventory developed by Rexler and Rezmovic (1981), and the Instructional Preference Questionnaire developed by Friedman and Stritter (1981), looked at students in classroom settings where learning styles were determined. (Data for the study addressed in this paper was collected from similar types of students in classroom settings).

\section{Hospitality-Related Studies}

A few studies specifically in the areas of the hospitality industry and in vocational education were conducted that sought to evaluate students and managers based on the learning style models discussed earlier. All of the researchers used either Kolb's Learning Style Model (1976) or Marshall and Merritt's (1984) adaptation of Kolb's model (Figure 2).

Heitmeyer and Thomas's (1990) research centered on post-secondary home economics students in majors of dietetics, child development, fashion merchandising, and home economics education. These authors wanted to examine the question of whether all majors in home economics had the same learning style. The use of two learning style models [Kolb's Learning Style Inventory (LSI) and Witkin, Oltman, Raskin and Karp (1971) Group Embedded Figures Test (GEFT)] classified these students into cognitive learning style categories. Students were classified in order that three hypotheses might be tested:- 1 . will the proportion of students in the different learning style categories be equal? 2. will there be difference in mean academic achievement among groups of students with different cognitive learning styles? and 3. will there be a relationship in the classification of student learning style categories as measured by the Witkin GEFT and Kolb LSI? Noting the similarities between Kolb's diverger category and Witkin's field independent category, the majority of the students fell into the field dependent category (50\%), and fewer into the field independent category $(30 \%)$.

Paulson, Baltzer, and Cole (1989) also looked at students in a hospitality programme. Again Kolb's LSI was used to measure learning styles. Their investigation found that of 135 students who took a pre-and post-test, a significant relationship existed between learning styles and cognitive achievement. They reported that they included $35.0 \%$ divergers, $38.6 \%$ assimilators, and $20.7 \%$ accommodators. Only $2 \%$ of the students were found to be convergers.

A common feature of two other studies reviewed (Berger, 1983 \& Hsu, 1989) was that both researchers used groups of students and, or managers in the hospitality industry. What is different about their studies is the result of their findings regarding learning styles.

Berger (1983) used three groups of students and faculty in a four-year hospitality management 
programme at Cornell University, and managers currently working in the industry who were graduates of the programme, She, like Paulson, Baltzer, and Cole used Kolb's LSI to obtain data. Scores obtained from Berger's study were used to characterize subjects as possessing one of Kolb's four learning styles converger, diverger, assimilator, or accommodator.

Hsu (1989) examined 118 unit managers and 45 district managers in hospitality operations. Hsu was the only other researcher, besides Marshall and Merritt (1984), who used the Learning Style Inventory with a semantic differential (LSI-SD).

Learning styles were measured in both studies, that resulted in apparent sharp differences. Most of the students were classified as divergers (33\%) and accommodators (29\%). Nineteen percent (19\%) of the students were either accommodators or assimilators, forty-two percent (42\%) of the 26 professors were convergers. Twenty-seven percent (27\%) were assimilators; fifteen percent (15\%) were accommodators, and fifteen percent $(15 \%)$ were divergers. Hospitality managers, on the other hand, produced thirty-two percent (32\%) accommodators and thirty-two percent (32\%) convergers of the 26 surveyed. The remainder were divergers $(26 \%)$ and assimilators (10\%).

Results from Hsu's (1989) study indicated that the learning style most prevalent among the unit managers was that of the converger (78\%). Of the district managers surveyed seventy-six percent $(76 \%)$ were predominantly convergers. This differed from Berger's (1983) study of managers who produced only $32 \%$ converger of those surveyed.

\section{METHODOLOGY AND DATA COLLECTION}

This study describes the learning styles of post-secondary vocational education students and hotel general managers in The Bahamas. The investigation also compares predominant learning styles among students grouped by programme and between the manager and student groups.

For this study, several learning style instruments were reviewed: Field Independence and Field Dependence developed by Witkin et al. (1975), Cognitive Style Mapping developed by Hill and Nunney (1972), Fuhrmann and Jacobs Model (1980), Kolb's Learning Style Inventory (LSI) (1976), and Learning Style Inventory with a semantic differential (LSI-SD) format by Marshall and Merritt (1984). The Learning Style Inventory developed by Marshall and Merritt (1984) was ultimately selected. These authors granted permission to use the LSI-SD that is based on Kolb's original LSI. The LSI-SD was considered to be reliable and have construct validity. Marshall and Merritt (1984) employed least squares factor analysis to examine the construct validity of the instrument. The LSI-SD trait scale reliabilities ranged from 0.61 to 0.86 , with a mean reliability of 0.77 .

The LSI-SD was selected because it was deemed culturally appropriate. Guest judges (faculty members from BHTC) were sent the LSI-SD to review prior to administration to students and managers. It was felt that neither the wording nor the use of the semantic differential format would present a major problem.

The Learning Style Inventory using the semantic differential was designed to assess individual learning styles within an experiential learning model. The instrument contains 40 items in a semantic differential format using a five-point response mode. The core of the LSI-SD reflects information processing. It depicts learning in the following four stages:

1. Concrete Experience (CE);

2. Reflective Observation (RO);

3. Abstract Conceptualization (AC);

4. Active Experimentation (AE).

These four traits form two orthogonal, bi-polar axes, with AC-CE being one axis and AE-RO being the other axis. Learning styles are classified into one of the four quadrants defined by these axes. The four learning styles that are defined are:

1. The Diverger - These people tend to be good at generating ideas, such as brainstorming. 
Their predominant learning traits are feeling (CE) and watching (RO);

2. The Assimilator - The predominant learning traits of these people are thinking (AC) and watching (RO). They tend to be good in inductive reasoning and interested in abstract conceptualization;

3. The Converger - These people tend to focus on the practical application of ideas. The predominant learning traits are thinking $(\mathrm{AC})$ and doing $(\mathrm{AE})$.

4. The Accommodator - The predominant learning traits are feeling (CE) and doing (AE). The accommodator's strength is in doing things and caring out plans.

The LSI-SD contains four scales having 10 items associated with each scale. The scales measure the four learning traits, $\mathrm{AC}, \mathrm{CE}, \mathrm{AE}$, and $\mathrm{RO}$. Each item is a bi-polar with a five-point response mode.

\section{Characteristics of Respondents}

Of the possible 125 full-time post-secondary vocational education students at The Bahamas Hotel Training College (BHTC), $94(75.2 \%)$ provided responses. A purposive sample was selected for this study. The LSI-SD, along with a demographic component for the students (DC-S) was administered over a one-week period to full-time students only, while they attended classes in the fall 1991. Full-time students from four different programmes (1) Ordinary National Diploma 17 Programme, (2) Ordinary National Diploma 18 Programme, (3) National Apprentice Chef Programme, and (4) Bahamas Certificate in Bookkeeping and Front Desk Skills, were administered the instrument.

Out of 50 possible general managers, 24 (48\%) gave responses. The LSI-SD along with a demographic component for the managers (DC-M) was administered in July and September 1991.

The software programme, SPSS Release 4.0 (SPSS, 1990) was used to analyze data. Descriptive statistics including frequencies, percentages, and means were calculated for the 40-item instrument as well as for the demographic characteristics. It should be noted that the scoring procedures from Kolb's original scoring procedure (1976) differed slightly from those used by Marshall and Merritt (1984) in that Marshall and Merritt used a variation on the axes to plot learning style positions. The sign of the values represented on the ACCE and AERO axes have been reversed. In addition, the ACCE dimension is calculated as CEAC for Marshall and Merritt, but AC-CE for Kolb. Likewise, AERO is calculated as RO-AE of Marshall and Merritt, but AE-RO for Kolb. This reversal of dimension formula and value representation on the axes did cause initial confusion even after several phone calls to Merritt. Because these contacts resulted in changing information on scoring procedure, the dimension formulas specified by Kolb (ACCE=AC-CE and $A E R O=A E-R O)$ and the grid position with negative values to the top and right of the $(0,0)$ origin were used.

The Kolmogorov-Smirnov goodness to fit test (Kolmogorov, 1941; Smirnov, 1948) was performed on the ACCE and the AERO axes to ensure that these dependent variables were normally distributed. The Kolmogorov-Smirnov

goodness to fit test determines the degree of agreement between the distribution of a set of sample values (observed scores) and some specified theoretical distribution.

Discriminant analysis was used as predictors of learning styles of respondents to severai independent variables. Common demographic characteristics (age, gender, Caribbean home) from both groups were used as independent variables. Cross-tabulation and chi-square analysis procedures were conducted to identify the overall proportions for each learning style quadrant by student and manager groups. 


\section{TABLE 1}

RESULTS AND DISCUSSION

DEMOGRAPHIC CHARACTERISTICS OF STUDENTS

\begin{tabular}{|c|c|c|}
\hline VARIABLES & FREQUENCY & PERCENT (\%) \\
\hline $\begin{array}{l}\text { Gender } \\
\text { Male } \\
\text { Female }\end{array}$ & $\begin{array}{l}34 \\
60 \\
94\end{array}$ & $\begin{array}{r}36.2 \\
63.8 \\
100.0\end{array}$ \\
\hline $\begin{array}{l}\text { Age group of students } \\
\text { Less than } 25 \text { years } \\
25 \text { to } 29 \text { years } \\
30 \text { to } 34 \text { years }\end{array}$ & $\begin{array}{r}88 \\
3 \\
3 \\
94\end{array}$ & $\begin{array}{r}93.6 \\
3.2 \\
3.2 \\
100.0\end{array}$ \\
\hline $\begin{array}{l}\text { Home in the Caribbean } \\
\text { Yes } \\
\text { No }\end{array}$ & $\begin{array}{r}90 \\
4 \\
94\end{array}$ & $\begin{array}{r}95.7 \\
4.3 \\
100.0\end{array}$ \\
\hline $\begin{array}{l}\text { Time in programme } \\
\text { New full-time student } \\
1 \text { year } \\
11 / 2 \text { years } \\
2 \text { years or over } \\
\text { Not a full-time student }\end{array}$ & $\begin{array}{r}40 \\
23 \\
9 \\
21 \\
1 \\
94\end{array}$ & $\begin{array}{r}42.5 \\
24.5 \\
9.6 \\
22.3 \\
1.1 \\
100.0\end{array}$ \\
\hline $\begin{array}{l}\text { Programme enrolled } \\
\text { Ordinary Diploma } 17 \\
\text { Ordinary Diploma } 18 \\
\text { National Apprentice Chef } \\
\text { Bookkeeping \& Front Desk }\end{array}$ & $\begin{array}{r}17 \\
53 \\
18 \\
6 \\
94\end{array}$ & $\begin{array}{r}18.1 \\
56.4 \\
19.1 \\
6.4 \\
100.0\end{array}$ \\
\hline Prior work in industry & & \\
\hline $\begin{array}{l}\text { Yes } \\
\text { No }\end{array}$ & $\begin{array}{l}34 \\
60 \\
94\end{array}$ & $\begin{array}{r}36.2 \\
63.8 \\
100.0\end{array}$ \\
\hline
\end{tabular}

For each variable on the demographic component for students form (DC-S), all respondents answered. No missing data occurred. 
Table 1 presents the overall response percentages for the demographic characteristics of the 94 full-time students. Sixty (63.8\%) were female and $34(36.2 \%)$ were male. Eighty-eight (93.6\%) students were less than 25 years old, and three (3.2\%) were between the ages of 25 and 29 . Another three (3.2\%) students were between the ages of 30 and 34 years old. About $95.7 \%$ percent of the students had permanent homes in the Caribbean.

There were four programmes in which students were enrolled in at The Bahamas Hotel Training College (BHTC). There were $17(18.1 \%)$ students in the Ordinary National Diploma 17 prograrnme. Fifty-three $(56.4 \%)$ students enrolled in the Ordinary National Diploma 18 programme. Eighteen $(19.1 \%)$ of the students were enrolled in the National Apprentice Chef Programme, and only six (6.4\%) of the students were enrolled in the Bookkeeping and Front Desk Skills Programme.

Table 2 presents a summary of the demographic characteristics of the 24 managers for whom 16 $(66.7 \%)$ were male and eight $(33.3 \%)$ were female. The age range of the managers varied somewhat, while the level of education or the highest degree received by the general managers produced some surprising results. Of the 24 general managers, eight $(33.3 \%)$ had only a high school diploma. Five (20.8\%) had a two-year hospitality-related degree, one (4.2\%) manager, a hospitality-related Bachelor's degree, six (25\%) managers held non-hospitality-related Bachelor's degree and four (16.7\%) of the general managers had an advanced degree, which included MBA, Ph.D., or some other graduate-level degree.

\section{DETERMINATION OF LEARNING STYLES}

Scores were computed for student and manager groups on the four learning traits which comprised the learning style model. These traits were identified as abstract conceptualization (AC), concrete experience (CE), active experimentation (AE), and reflective observation (RO). Based on the LSI-SD model that was used, individuals participating in the study could possibly end up with any one out of the following four learning styles: converger, diverger, accommodator or, assimilator.

Means for learning traits and learning dimensions are reported in Table 3. Using the combined data set (student and manager groups), the ACCE and AERO dimensions were submitted to the Kolmogorov-Smirnov goodness to fit test. The Kolmogorov-Smirnov goodness to fit test indicated that both the ACCE $(\mathrm{K}-\mathrm{S}$ test $=.682, \mathrm{p} .=.742)$ and the AERO $(\mathrm{K}-\mathrm{S}$ test $=.851, \mathrm{p}=.464)$ axes were distributed normally.

\section{FINDINGS}

Of the 94 full-time students surveyed, 44 (46.8\%) had a diverger learning style, $17(18.1 \%)$ were accommodators, nine $(9.6 \%)$ were convergers, and the $15(16 \%)$ remaining students were assimilators. Of the managers participating in this study, $21(87.5 \%)$ were divergers and three $(12.5 \%)$ were assimilators. Table 3 shows the comparison between students' and managers' learning styles. Student scores were calculated using only 85 students. Nine students whose learning styles could not be classified because their scores, when plotted, fell on the ACCE or AERO axis were dropped from further analysis. Chi-square results $(X=11.65$, d.f. $=3)$ indicated that when compared, differences in learning styles for the student and manager groups were statistically at the .05 level. 
TABLE 2

DEMOGRAPHIC CHARACTERISTICS OF MANAGERS

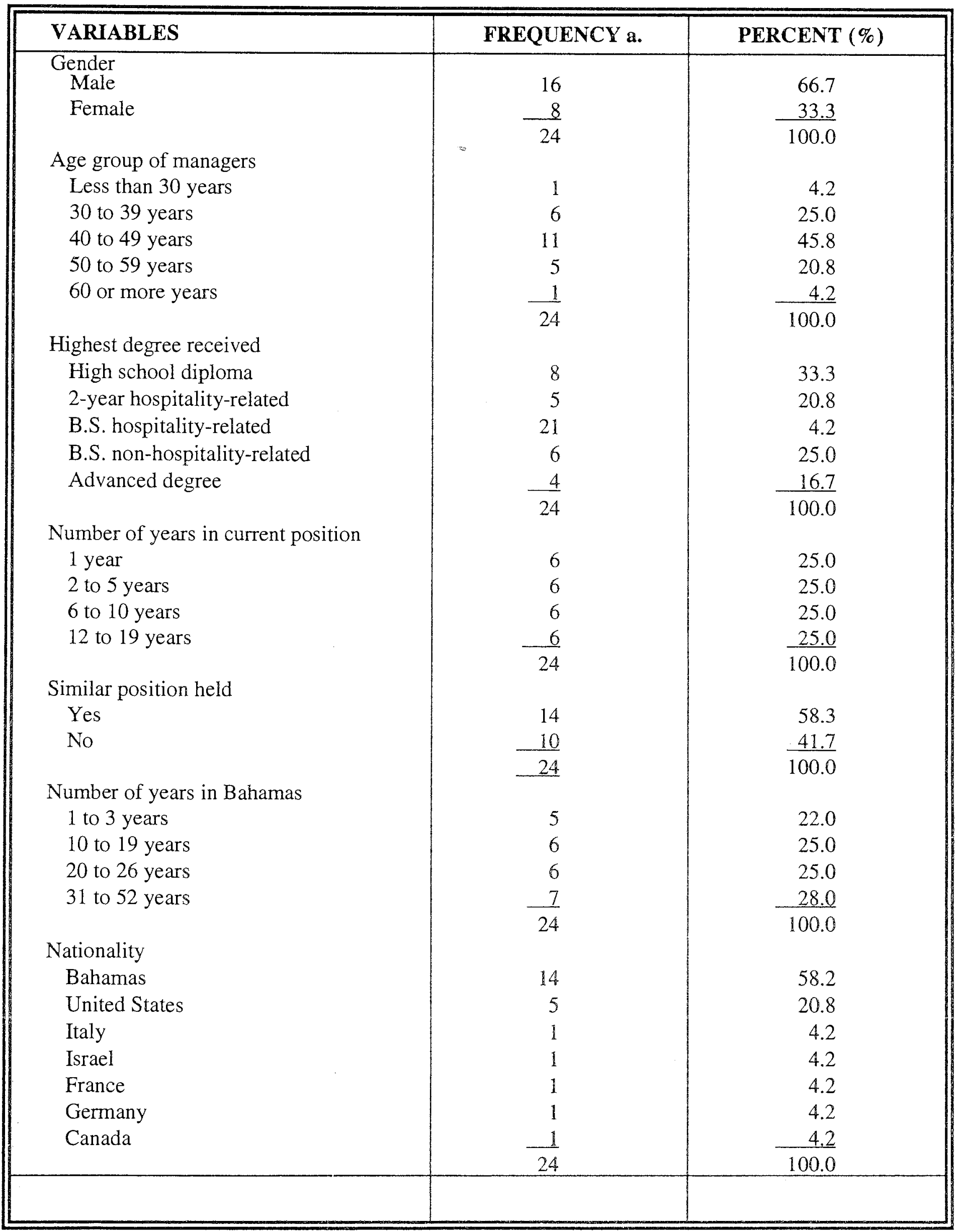


a. For each variable on the demographic component for managers form (DC-M), all respondents answered. No missing data occurred.

b. Categories were determined by collapsing data points rather than determining equal size intervals. There were no data counts between labelled categories.

TABLE 3

LEARNING STYLES OF STUDENTS AND MANAGERS

\begin{tabular}{|c|c|c|c|c|}
\hline \multirow{2}{*}{ LEARNNG STYLES } & \multicolumn{2}{|c|}{ STUDENTS } & \multicolumn{2}{|c|}{ MANAGERS } \\
\hline & FREQUENCY & PERCENT(\%) & FREQUENCY & PERCENT(\%) \\
\hline Diverger & 44 & 51.8 & 21 & 87.5 \\
\hline Accommodator & 17 & 20.0 & 0 & 0.0 \\
\hline Converger & 9 & 10.6 & 0 & 0.0 \\
\hline Assimilator & 15 & 17.6 & 3 & 12.5 \\
\hline Total & 85 & 100.0 & 24 & 100.0 \\
\hline
\end{tabular}

Nine students were excluded because they were not able to be classified.

Generally, when student learning styles were compared to programmes at BHTC, the results were consistent with the number of years that they were enrolled at the college. Only three programmes (Ordinary National Diploma 17, Ordinary National Diploma 18, and National Apprentice Chef Programme) were included in the chi-square analysis, because the overall count for students in the Bookkeeping and Front Desk Skills Programme was too low. Table 4. indicates the percentage of students and their learning styles by programme. When chi-square results were compared $(X=8.32$, d.f. $=9)$, the differences in leaming styles for students in the three programmes were not statistically significant.

\section{TABLE 4}

\section{LEARNING STYLES OF STUDENTS BY ENROLLED PROGRAMME}

\begin{tabular}{|c|c|c|c|c|c|c|}
\hline \multirow{3}{*}{$\begin{array}{l}\text { LEARNING } \\
\text { STYLES }\end{array}$} & \multicolumn{6}{|c|}{ ORDINARY NATIONAL } \\
\hline & \multicolumn{2}{|c|}{ Diploma 17} & \multicolumn{2}{|c|}{ Diploma 18} & \multicolumn{2}{|c|}{ Apprentice Chef } \\
\hline & $\mathbf{N}$ & $\%$ & $\mathbf{N}$ & $\%$ & $\mathbf{N}$ & $\%$ \\
\hline Diverger & 7 & 43.8 & 26 & 56.5 & 8 & 47.1 \\
\hline Accommodator & 3 & 18.8 & 9 & 19.6 & 5 & 29.4 \\
\hline Converger & 3 & 18.8 & 4 & 8.7 & 2 & 11.8 \\
\hline Assimilator & 3 & 18.8 & 7 & 15.2 & 2 & 11.8 \\
\hline Total & 16 & 100.0 & 46 & 100.0 & 17 & 100.0 \\
\hline
\end{tabular}




\section{DISCUSSION}

As females generally outnumber males at the post-secondary level in The Bahamas, the demographic characteristics reported in this study were somewhat predictable in that of the 94 students, males accounted for slightly less than one-third while two-thirds were females. In addition, 88 (93.6\%) students were less than 25 years old. With more females entering management roles in the hospitality industry, this finding seems to support their desire to develop appropriate skills.

The Ordinary National Diploma Programme accounted for $53(56.4 \%)$ of all the full-time students in the school. Also, these students were more apt to be present on the first day of classes, because they are not familiar with the school system as are returning students in the other programmes and, therefore, were anxious not to miss anything.

Several unexpected findings were revealed upon examination of the demographic data of the managers. Out of the 24 general managers surveyed, eight were female, and 16 were male. This distribution was surprising, because even though the hospitality industry is thought of as a very male-dominated industry, the proportion of females in general management positions is increasing. The other surprising finding was that eight out of the 24 managers had only a high school diploma. This constituted one-third of the general managers who supervised 300 -plus room hotels. Two conditions may have contributed to this fact. First, many of the managers were between the ages of 40 and 49 , and there was not much emphasis placed on obtaining a degree in hospitality management when they first entered the hospitality industry. More emphasis was placed on learning a vocational trade which would assist individuals to support their families. Second, many of these managers had no formal training, but moved up through the ranks of the industry. After a period of time, due to seniority and/or years of experience in the industry, the position of general manager became vacant and was offered to them. This conjecture seems to be supported by the fact that 12 of the managers were in the position of general manager for 10 to 19 years, while the remaining 14 were at the managerial level to which they were initially appointed. A significant number of the managers (21), and 44 students had a diverger learning style. Skills of a person with the diverger learning style, according to Kolb (1984) and Marshall and Merritt (1984), are brainstorming ideas, having imaginative abilities, understanding people, and recognizing problems. From the researcher's personal experience in the industry, these skills seem to be the preferred skills for managers as they work with hospitality industry personnel. In comparing the results of the managers and students in this study with those of other studies in the hospitality industry, there is only partial agreement on learning style classification. A review of Figure 2. indicates that results appear similar in some cases, while in other cases they varied sharply. For example, when comparing the learning styles of managers in this study with those of Hsu (1989) and Berger (1983), cross-tabulations indicate that the majority of the managers in these previous studies were convergers. No convergers were identified in this study, however, and the predominant learning style of Bahamian general managers was diverger. When comparing the results of learning styles of students in this study with those of Berger (1983), Heitmeyer and Thomas (1990), and Paulson et al. (1989), the majority in all these studies had a diverger learning style.

\section{IMPLICATIONS}

The study examined the learning styles of post-secondary vocational education students majoring in hospitality and hotel managers in the Bahamas. Results were compared to similar studies conducted in the United States. Because of the treatment of missing data and the lower response rate for hotel general managers, findings from this study should be considered with some caution. Nevertheless, it appears that further investigation of the LSI-SD should be conducted to determine if it is an appropriate alternate form for the LSI. The problem of unclassified cases may be one which has merely gone unreported in earlier studies which used the LSI-SD. 


\section{SUMMARY AND CONCEUSION}

This study was designed to determine the learning styles of post-secondary vocational education students and hotel gencral managers in the Bahamas. It was also designed to determine whether the predominant learning styles of both groups were similar and how the learning styles of students in the four full-time programmes at BHTC compared.

Based on the findings of the study, two important conclusions were derived. Computation of all data in this study revealed that (a) a majority of both the students (51.8\%) and managers (87.5\%) had a diverger learning style; and (b) when examining students' learning style by programme for the three programmes with adequate numbers for comparison, a majority of the students represented in each programme had a diverger learning style. In addition, there were some concerns regarding instrumentation that emerged. The Marshall and Merritt LSI-SD does not account for those individuals whose score fall on the ACCE or AERO axes, or at the origin. In Kolb's original LSI this problem is not evident, because the axes he used were calibrated at the 50th percentile, thus using decimal numbers (approximately 3.8, 5.9) rather than whole numbers for the coordinates of the origin. Using the Marshall and Merritt LSI-SD with the ACCE and AERO intersecting at 0,0 coordinates resulted in $10 \%$ of the cases not being classified. Researchers contemplating use of the Marshall and Merrit1 LSI-SD for future research in this industry might well be advised to conduct a further examination of the appropriateness of the use of this adaptation of Kolb's Learning Style Instrument as a good substitute. This study has the potential to impact the hospitality industry of The Bahamas in the following ways:

1. Results of this study can assist BHTC programme directors as they plan vocational courses which mect the curriculum objectives of the programme and those of the Ministries of Education andTourism.

2. Studies can be conducted that further investigate student learning styles at BHTC utilizing various learning style models.

3. When presented to the Ministry of Education, results of this study may be considered in the planning stages of a new four year hotel training programmes.

4. This study also adds to the body of knowledge relating to international vocational education.

5. This study provides educators in the hospitality Industry with information and implications for how to select students for their programmes, provided that a learning style model is used in the application process of the students. 


\section{REFERENCES}

1. BERGER, F. (1983). Disparate learning styles of hospitality students, professors and managers. International Journal of Hospitality Management, 2(1), pp.15-23.

2. FRIEDMAN, C., \& Stritter, F. (1981). Instructional Preference Questionnaire. University of North Carolina, Office of Medical Studies, Chapel Hill.

3. FUHRMANN, B.S., \& Jacobs, R. (1980). The Learning Interaction Inventory. Richmond: Ronne Jacobs Associates.

4. Handbook of the Industrial Training Center. (1991). Nassau Bahamas: Industrial Training Center.

5. HEITMEYER, J.R. \& Thomas, B.B. (1990). Cognitive learning style dimensions in post-secondary home economics students. Journal of Studies in Technical Careers, 7(2), pp.139-153.

6. HILL, J., \& Nunney, D.N. (1972). Personalized programmes. Audio Visual Instructor, 14, pp.2530.

7. HSU, H.C. (1989). Restaurant managers learning styles: Implications for management development programmes. DA150/06A, p.1580, Iowa State University, Ames, IA.

8. KOLB, D.A. (1976). The learning style inventory: Technical manual. Boston: McBer.9. KOLB, D.A. (1984). Experiential learning. Englewood Cliffs, NJ: Prentice-Hall.

10. KOLMOGOROV, A. (1941). Confidence limits for an unknown distribution function. Annals of Mathematical Statistics, 12, pp.461-463.

11. MARSHALL, J.C., \& Merritt, S.L. (April 1984). Reliability and construct validity of ipsative and normative forms of the learning style inventory. Educational and Psychological Measurement, 44, pp.463472.

12. PAULSON, D.M., Baltzer, L.E. \& Cole, R.S. (1989). Methods of educating cashiers in a restaurant teaching Jaboratory. Hospitality Education and Research Journai, 13 (2), pp.31-44.

13. REZLER, A.G., \& Rezmovic, V. (1981). The learning preference inventory. Journal of Applied Health, 10, pp.28-34.

14. SMIRNOV, N.V. (1948). Table for estimating the goodness of fit of empirical distributions. Annals of Mathematical Statistics, 19, pp.279-281.

15. WITKIN, H.A., Goodenough, D.R., \& Oltman, P.K. (1977). Rokle of field-dependent and fieldindependent cognitive styles in academic evolution: A longitudinal study. Journal of Education Psychology, 69, pp.197-211.

16. WTTKIN, H.A., Oltman, P.K., Raskin, E., \& Karp, S.A. (1971). A manual for the embedded figures test. Palo Alto: Consulting Psychologists Press. 


\section{AUTHOR}

Sophia Rolle is currently a Lecturer of Tourism Studies in the Division of Social Sciences at The College of The Bahamas. She also acts in the capacity of Coordinator of the Tourism Studies Programme. Sophia has attended and presented at a number of hospitality-related conferences, and has a varied amount of managerial and teaching experiences in the national and international arena. During Sophia's tenure at The College, she is expected to extensively market and increase the enrollment of the Tourism Studies Programme.

Dr. Sophia Rolle received her early training in hotel management from the Bahamas Hotel Training College. She went on to receive a Bachelor of Science Degree in Business Management from St. Augustine's College. On receiving a full academic scholarship, Sophia attended Iowa State University where both the Master of Science Degree and the Doctor of Philosophy Degree were received in five years. Both degrees were in the field of Hospitality Management.

Sophia is very actively involved in a number of professional organizations both on the international level as well as the national level. Internationally, Sophia is a member of the Council on Hotel, Restaurant and Institutional Educators, Club Managers Association of America, and Phi Delta Kappa an intemational honour society. On the national level, Dr. Rolle is actively involved with The Bahamas Business and Professional Women's Club, where she serves as Secretary, Delta Sigma Theta Sorority Incorporated, the Diocesan Chorale and many others. 